\title{
Central nervous system tumors: a single center pathology review of 34,140 cases over 60 years
}

\author{
Liang Chen ${ }^{1+}$, Xiang Zou ${ }^{1+}$, Yin Wang ${ }^{2}$, Ying Mao ${ }^{1}$ and Liangfu Zhou ${ }^{1 *}$
}

\begin{abstract}
Background: Tumor epidemiology is a significant part of CNS (central nervous system) tumor studies. Reassessment of original sections can update our knowledge of tumor spectrum. Here, we discuss the features of CNS tumor pathology in a single center.

Methods: A total of 34140 cases from 1950 to 2009 were collected; sections from 1990 to 2009 were reassessed according to WHO 2007 classification, and cases from 1950 to 1989 were classified according to the previous pathological diagnosis.

Results: Seven CNS tumor categories during 1990 to 2009 were as follow: neuroepithelial tissue (38.0\%), tumors of the meninges (36.5\%), tumors of the sellar region (4.1\%), germ cell tumors (1.3\%), tumors of cranial and paraspinal nerves (13.3\%), lymphomas and hematopoietic neoplasm (1.7\%), metastatic tumors (5.1\%), where histological types by age and sex were diverse. Overall, males exceeded females in distributions of most CNS tumor subtypes, while tumors of the meninges occurred more frequently in females. The case number of lymphomas and hematopoietic neoplasms grew the fastest during the past five years, and the distribution of neuroepithelial tumors remained stable over the past twenty years.
\end{abstract}

Conclusions: Despite the possibilities of cross sample biases, the data in this series could suggest a similar CNS tumor spectrum as might occur in other developing countries.

Keywords: Central nervous system tumors, Epidemiology, Pathological review, Single center, WHO 2007 classification

\section{Background}

Central nervous system (CNS) tumors are not as frequent as tumors of many other sites, such as those of the reparative or digestive systems [1], but their incidence rate has increased over time. A report from the International Agency for Research on Cancer (IARC) revealed that the worldwide incidence rate of CNS tumors in 2002, which was ageadjusted and considered the standard world population, was 3.7/100,000 persons among males and 2.6/100,000 persons among females. The incidence rates were higher in developed countries (males: 5.8/100,000 persons; females: 4.1/ 100,000 persons) than in less developed countries (males: $3.0 / 100,000$ persons; females: $2.1 / 100,000$ persons) [2]. In 2008, the rates had risen to $3.8 / 100,000$ persons in males

\footnotetext{
*Correspondence: Ifzhouc@126.com

†Equal contributors

'Department of Neurosurgery, Huashan Hospital, Fudan University, 12 Wu Lu Mu Qi Zhong Road, Jing An District, Shanghai 200040, China Full list of author information is available at the end of the article
}

and 3.1/100,000 persons in females, although the incidence rates in developed countries (males: 5.8/100,000 persons; females: 4.4/100,000 persons) still remained higher than those in less developed countries (males: 3.2/100,000 persons; females: $2.8 / 100,000$ persons). An overall increase has been observed throughout the world, especially in less developed countries, which has captured our attention.

The Neurosurgical Department in Huashan Hospital is a main clinical center for neurological diseases in China. In this study, we retrospectively retrieved the neuropathological data obtained from our hospital during the period of 1950-2009 and analyzed the spatiotemporal changes relative to the published data over the past six decades from other countries.

\section{Methods}

This study was performed at the Neurosurgical Department of the Huashan Hospital, Fudan University. Ethical approval

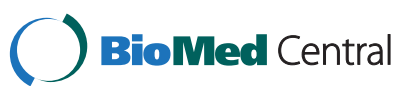




\begin{tabular}{|c|c|c|c|c|c|}
\hline & $\mathrm{N}(\%)$ & $M$ & $F$ & Ma(yrs) & Ma(yrs) \\
\hline \multicolumn{6}{|l|}{ I. Tumors of neuroepithelial tissue } \\
\hline \multicolumn{6}{|l|}{ 1. Astrocytic tumors } \\
\hline Pilocytic astrocytoma & $469(1.69)$ & 253 & 214 & 21.1 & 17 \\
\hline Pilomyxoid astrocytoma & $20(0.07)$ & 8 & 12 & 19.2 & 17 \\
\hline Subependymal giant cell astrocytoma & $27(0.10)$ & 15 & 12 & 16.2 & 13 \\
\hline Pleomorphic xanthoastrocytoma & $67(0.24)$ & 33 & 34 & 28.4 & 23 \\
\hline Glioblastoma & $2170(7.81)$ & 1362 & 805 & 50.2 & 53 \\
\hline Giant cell glioblastoma & $12(0.04)$ & 9 & 3 & 42.7 & 41 \\
\hline Gliosarcoma & $64(0.23)$ & 39 & 25 & 48.8 & 50.5 \\
\hline Anaplastic astrocytoma & $939(3.38)$ & 593 & 346 & 49.2 & 42 \\
\hline Gliomatosis cerebri & $3(0.01)$ & 2 & 1 & 59 & 62 \\
\hline \multicolumn{6}{|l|}{ 2. Oligodendroglial tumors } \\
\hline Oligodendroglioma & $990(3.56)$ & 555 & 426 & 38.6 & 39 \\
\hline Anaplastic oligodendrogliom & $534(1.92)$ & 313 & 221 & 43.5 & 44 \\
\hline \multicolumn{6}{|l|}{ 3. Oligoastrocytic tumors } \\
\hline Oligoastrocytoma & $243(0.87)$ & 143 & 100 & 38.9 & 39 \\
\hline Anaplastic oligoastrocytoma & $89(0.32)$ & 56 & 33 & 44.7 & 46 \\
\hline \multicolumn{6}{|l|}{ 4. Ependymal tumors } \\
\hline Ependymoma & $623(2.24)$ & 350 & 273 & 37 & 38 \\
\hline Subependymoma & $39(0.14)$ & 21 & 18 & 43 & 43 \\
\hline Anaplastic ependymoma & $223(0.80)$ & 129 & 93 & 30 & 30 \\
\hline \multicolumn{6}{|l|}{ 5. Choroid plexus tumor } \\
\hline Choroid plexus papilloma & $91(0.33)$ & 34 & 57 & 29 & 29 \\
\hline Atypical choroid plexus papilloma & $2(0.01)$ & 0 & 2 & 37.5 & 37.5 \\
\hline Choroid plexus carcinoma & $11(0.04)$ & 8 & 3 & 31.6 & 25 \\
\hline \multicolumn{6}{|l|}{ 6. Other neuroepithelial tumors } \\
\hline Chordoid glioma of the third ventricle & $3(0.01)$ & 1 & 2 & 31.3 & 27 \\
\hline Astroblastoma & $4(0.01)$ & 2 & 2 & 37.8 & 42 \\
\hline \multicolumn{6}{|l|}{ 7. Neuronal and mixed neuronal-glial tumors } \\
\hline Cerebellar liponeurocytoma & $1(0.00)$ & 1 & 0 & 59 & 59 \\
\hline Desmoplastic infantile astrocytoma/ganglioglioma & $5(0.02)$ & 1 & 4 & 16.8 & 11 \\
\hline Dysembryoplastic neuroepithelial tumor & $54(0.19)$ & 34 & 20 & 22.6 & 17.5 \\
\hline Dysplastic gangliocytoma of cerebellum, Lhermitte-Duclos & $7(0.03)$ & 3 & 4 & 28.7 & 38 \\
\hline Rosette-forming glioneuronal tumor of the fourth ventricle & $4(0.01)$ & 0 & 4 & 28.3 & 24 \\
\hline Paraganglioma & $29(0.10)$ & 14 & 15 & 42.5 & 42 \\
\hline Papillary glioneuronal tumor & $13(0.05)$ & 9 & 4 & 32.4 & 29 \\
\hline Anaplastic ganglioglioma & $43(0.15)$ & 26 & 17 & 39.7 & 41 \\
\hline Gangliocytoma & $40(0.14)$ & 29 & 11 & 29.6 & 31.5 \\
\hline Ganglioglioma & $137(0.49)$ & 87 & 49 & 33.1 & 32 \\
\hline Central neurocytoma & $131(0.47)$ & 63 & 68 & 30.2 & 29 \\
\hline \multicolumn{6}{|l|}{ 8. Tumors of pineal region } \\
\hline Papillary tumor of the pineal region & $2(0.01)$ & 1 & 1 & 31.5 & 31.5 \\
\hline Pineocytoma & $15(0.05)$ & 5 & 10 & 30.3 & 22 \\
\hline
\end{tabular}


Table 1 Histological features of 27802 cases from 1990 to 2009 (Continued)

\begin{tabular}{|c|c|c|c|c|c|}
\hline Pineal parenchymal tumor of intermediate differentiation & $5(0.02)$ & 5 & 0 & 26.8 & 20 \\
\hline Pineoblastoma & $10(0.04)$ & 5 & 5 & 25.6 & 17.5 \\
\hline \multicolumn{6}{|l|}{ 9. Embryonal tumors } \\
\hline Medulloblastoma & $515(1.85)$ & 329 & 183 & 15.4 & 12 \\
\hline PNET & $119(0.43)$ & 75 & 43 & 21.9 & 17 \\
\hline Atypical teratoid/rhabdoid tumor & $4(0.01)$ & 2 & 2 & 21.8 & 23 \\
\hline \multicolumn{6}{|l|}{ II. Tumors of cranial and paraspinal nerves } \\
\hline 1. Schwannoma (neurilemoma, neurinoma) & 3499 (12.59) & 1754 & 1736 & 45 & 45 \\
\hline 2. Neurofibroma & $166(0.60)$ & 106 & 60 & 36.3 & 38 \\
\hline 3. Perineurioma & $1(0.00)$ & 0 & 1 & 69 & 69 \\
\hline 4. MPNST & $26(0.09)$ & 11 & 15 & 37.8 & 42 \\
\hline \multicolumn{6}{|l|}{ III. Tumors of meninges } \\
\hline \multicolumn{6}{|l|}{ 1. Tumors of meningothelial cells } \\
\hline Grade I meningothelial cells tumors & $7623(27.42)$ & 2294 & 5309 & 50.7 & 51 \\
\hline Atypical & $359(1.29)$ & 184 & 173 & 51.2 & 52 \\
\hline Chordoid & $16(0.06)$ & 8 & 8 & 48.5 & 51 \\
\hline Clear cell & $30(0.11)$ & 13 & 17 & 37.5 & 39.5 \\
\hline Papillary & $26(0.09)$ & 16 & 10 & 36.7 & 35.5 \\
\hline Rhabdoid & $15(0.05)$ & 9 & 6 & 42.2 & 42 \\
\hline Anaplastic, malignant & $235(0.85)$ & 129 & 105 & 50.3 & 50 \\
\hline \multicolumn{6}{|l|}{ 2. Mesenchymal tumors } \\
\hline Hemangiopericytoma & $202(0.73)$ & 112 & 88 & 43.3 & 42 \\
\hline Anaplstic hemangiopericytoma & $8(0.03)$ & 5 & 3 & 48.3 & 45.5 \\
\hline Other Mesenchymal tumors & $825(2.97)$ & 450 & 369 & 36 & 37 \\
\hline \multicolumn{6}{|l|}{ 3. Primarymelanocytic lesions } \\
\hline Diffuse melanocytosis & $2(0.01)$ & 1 & 1 & 35.5 & 35.5 \\
\hline Melanocytoma & $9(0.03)$ & 5 & 4 & 47 & 47 \\
\hline Malignantmelanoma & $31(0.11)$ & 21 & 10 & 42.2 & 42 \\
\hline \multicolumn{6}{|l|}{ 4. Other neoplasms related to the meninges } \\
\hline Hemangioblastoma & $760(2.73)$ & 463 & 293 & 40.8 & 40 \\
\hline IV. Lymphomas and hematopoietic neoplasms & $464(1.67)$ & 272 & 191 & 49.7 & 52 \\
\hline \multicolumn{6}{|l|}{ V. Germ cell tumors } \\
\hline 1. Germinoma & $204(0.73)$ & 148 & 56 & 17.4 & 16 \\
\hline 2. Embryonal carcinoma & $14(0.05)$ & 12 & 2 & 12.2 & 12.5 \\
\hline 3. Yolk sac tumor & $2(0.01)$ & 2 & 0 & 7 & 7 \\
\hline 4. Choriocarcinoma & $1(0.00)$ & 0 & 1 & 34 & 34 \\
\hline 5. Teratoma & $10(0.04)$ & 8 & 2 & 14.5 & 14 \\
\hline Mature & $56(0.20)$ & 36 & 20 & 23.5 & 20.5 \\
\hline Immature & $22(0.08)$ & 20 & 2 & 16 & 14.5 \\
\hline With malignant transformation & $4(0.01)$ & 4 & 0 & 13.3 & 14 \\
\hline 6. Mixed germ cell tumors & $35(0.13)$ & 29 & 6 & 16.6 & 14 \\
\hline \multicolumn{6}{|l|}{ VI. Tumors of the sellar region } \\
\hline Craniopharyngioma & $1144(4.11)$ & 665 & 477 & 32.1 & 33 \\
\hline Granular cell tumor & $7(0.03)$ & 2 & 5 & 49 & 52 \\
\hline
\end{tabular}


Table 1 Histological features of 27802 cases from 1990 to 2009 (Continued)

\begin{tabular}{lrrrr}
\hline \multicolumn{1}{c}{ Pituicytoma } & $1(0.00)$ & 1 & 0 & 45 \\
$\quad$ Spindle cell oncocytoma of the adenohypophysis & $1(0.00)$ & 1 & 0 & 24 \\
VII. Metastatic tumors & $1431(5.15)$ & 890 & 536 & 53.9 \\
Total & 27802 & 13945 & 13774 & 55 \\
\hline
\end{tabular}

$\boldsymbol{N}=$ Number $\boldsymbol{M}=$ Male; $\boldsymbol{F}=$ Female;

$\boldsymbol{M a}=$ Median age at diagnosis; $\boldsymbol{m a}=$ Mean age at diagnosis;

PNET = Primitive neuroectodermal tumor;

Grade I meningothelial cells tumors = Meningiothelial; Fibrous, fibroblastic; Transitional, mixed; Psammomatous; Angiomatous; Microcystic; Secretory; Lymphop lasmacyte-rich; Metaplastic.

Other mesenchymal tumors = Lipoma; Angiolipoma; Hibernoma; Liposarcoma; Solitary fibrous tumor; Fibrosarcoma; Malignant fibrous histiocytoma; Leiomyoma; Leiomyosarcoma; Rhabdomyoma; Rhabdomyosarcoma; Chondroma; Chondrosarcoma; Osteoma; Osteosarcoma; Osteochondroma; Hemangioma; Angiosarcoma; Kaposi sarcoma; Ewing sarcoma-PNET.

MPNST = Malignant peripheral nerve sheath tumor.

was granted by the ethics committee of Huashan Hospital. The cases in this report were collected from patients who were diagnosed with CNS tumors and who were surgically treated or received biopsies between 1950 and 2009. Due to the loss of the original pathological sections, the cases from 1950 to 1989 could not be reassessed directly. In those cases, crude classifications were performed according to the previous pathological diagnoses that were used and adopted by neurosurgeons and neuropathologists at the time. However, our cases from 1990 to 2009 were reassessed by neuropathologists from the Neuropathology Department of Huashan Hospital according to the standards from the 2007 World Health Organization (WHO) classification [3].

All the CNS tumors were divided into seven categories: tumors of neuroepithelial tissue; tumors of the cranial and paraspinal nerves; tumors of the meninges; lymphomas and hematopoietic neoplasms; germ cell tumors; tumors of the sellar region; and metastatic tumors. Some differences exist between the WHO 2007 and WHO 2000 classifications; for example, gliomatosis cerebri was newly included in astrocytic tumors, and pilomyxoid astrocytoma was added as a new subtype in pilocytic astrocytoma. Consequently, we reassessed all the pilocytic astrocytoma cases to separate the cases of pilomyxoid astrocytoma from the old histological diagnoses. Extraventricular neurocytoma, papillary glioneuronal tumor, and rosette-

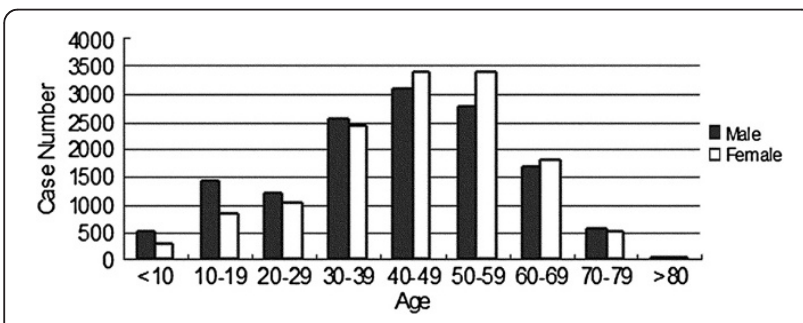

Figure 1 Distribution of CNS tumors by age and sex from 1990 to 2009. forming glioneuronal tumor of the fourth ventricle were added to a neuronal and mixed neuronal-glial tumors subtype. Angiocentric glioma was grouped with other neuroepithelial tumors. For choroid plexus, atypical choroid plexus papilloma was inserted between choroid plexus papilloma and choroid plexus carcinoma [4].

The WHO classification offers a crude histological grading system, in which each CNS tumor is classified as grade I-IV according to its degree of malignancy. This system can provide an estimate for the prognosis of a patient. In this study, age, sex, and the tumor histological type and grade were systematically recorded. In the detailed classified cases (1990-2009), the gender data were lost for 83 of the patients, and the age data were lost for 180 of the patients, representing $0.30 \%$ and $0.65 \%$ of the total, respectively. Consequently, we excluded the lost gender or age cases in the statistics of the sample. All the data analyses were performed using SPSS (Statistical Package for the Social Sciences) software.

Table 2 Distributions of CNS tumors and top 4 subtypes among children and teenagers (age 0-19)

\begin{tabular}{lrrrr}
\hline Tumor & N & M & F & \% \\
\hline Tumors of neuroepithelial tissue & 1791 & 1086 & 700 & 61.3 \\
$\quad$ Astrocytoma & 853 & 489 & 361 & 29.2 \\
$\quad$ Medulloblastoma & 383 & 254 & 128 & 13.1 \\
$\quad$ Ependymal tumours & 180 & 113 & 67 & 6.2 \\
& 378 & 231 & 157 & 12.9 \\
Tumors of the sellar region & 358 & 224 & 134 & 12.3 \\
& 326 & 204 & 120 & 11.2 \\
Tumors of the meninges & 237 & 182 & 54 & 8.1 \\
Germ cell tumors & 163 & 94 & 69 & 5.6 \\
Tumors of cranial and paraspinal nerves & 21 & 16 & 5 & 0.7 \\
Lympnomas and hematopoietic neoplasms & 6 & 3 & 3 & 0.2 \\
Metastatic tumors & 2922 & 1816 & 1108 & 100 \\
\hline Total & & &
\end{tabular}

$\boldsymbol{N}=$ Number $\boldsymbol{M}=$ Male; $\boldsymbol{F}=$ Female. 


\section{Results}

\section{General features}

From 1950 to 1989, 6338 cases could be grouped according to their CNS tumors based on our crude classification. Among these cases, 3530 were male, 2734 were female, and 935 were children and teenagers (age 0-19). Further details are provided in Additional files 1 and 2.

From 1990 to 2009, 27,802 out of 43,595 cases with brain disease could be grouped into CNS tumors according to the 2007 WHO classification system. The other diseases included pituitary adenoma for 7843 cases, cavernous malformation for 1247 cases, arteriovenous malformation for 848 cases, and other CNS diseases for 5854 cases (epidermoid cysts, parasites, abscesses, and others). The proportion of CNS tumors was $63.8 \%$. Among these cases, 13945 were males, 13774 were females, and 2903 were children and teenagers (age 0-19). The distribution of the CNS tumors by histological subtypes is shown in Table 1. Of the malignant tumors, glioblastoma was the most common, with a proportion of $29.5 \%$. Metastatic tumor was the next common and represented $19.4 \%$ of the total. These tumor types were followed by anaplastic astrocytomas, anaplastic oligodendromas, and others. The details are presented in Table 1. A few rare CNS tumors were encountered in this series, including new entities in the 2007 WHO classification, such as anaplastic hemangiopericytoma (8 cases), papillary tumors of the pineal region ( 2 cases), atypical choroid plexus papillomas (2 cases), rosette-forming glioneuronal tumor of the fourth ventricle (4 cases), and papillary glioneuronal tumors (13 cases).

\section{Histological types by age and sex}

Gender differences in morbidity were common in many of the subtypes. From 1962 to 1989, all the CNS tumor subtypes (except tumors of the meninges) occurred more frequently in males (Additional file 1). Additionally, from 1990 to 2009, neuroepithelial tumors (the most common category) were observed more frequently in male patients, with a ratio of 1.47 according to this survey. Tumors of the meninges exhibited a female/male ratio that exceeded 1.7

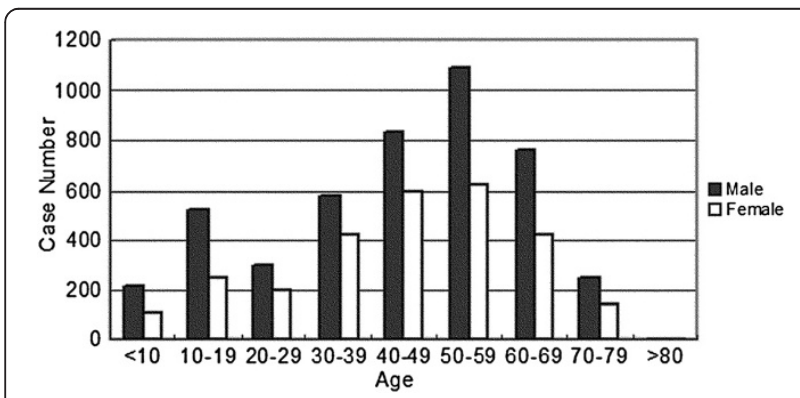

Figure 2 Distribution of malignant tumors (WHO III-IV) by age and sex from 1990 to 2009. according to our data (Table 1), whereas males were more susceptible to germ cell tumors, with a ratio of 2.91 .

The tumor distribution by age is another impressive aspect of brain tumor epidemiology. The histogram presented in Figure 1 shows a peak proportion within the age range from 30 to 60 in males, whereas the female patients seemed to peak at an older age relative to the males. There was another proportional peak from 10 to 19 years of age in the male patients, and malignant tumors tended to occur more frequently at that age. In adults, the top three subtypes included tumors of the meningothelial cells (33.6\%), schwannoma (14.2\%), and astrocytic tumors (11.4\%). For children and teenagers (age 0-19), astrocytomas were the most common CNS tumors $(29.2 \%)$, followed by medulloblastoma (13.1\%) and craniopharyngioma (12.3\%) (Table 2).

For the WHO III-IV grade tumors, two incidence peaks were identified in both male and female patients, with malignant tumors occurring more often in males at each age group (Figure 2). The spectra of the malignant tumors were different in the pediatric and adult groups (Figure 3). For the adults, glioblastoma, metastatic tumor, and anaplastic astrocytoma occupied the top three places. However, for the pediatric cases (age 0-19), the top three malignant tumors included medulloblastoma, germ cell tumors, and glioblastoma.

\section{Time trends over the 60 -year period}

Over the past six decades, the number of patients has grown tremendously. In contrast to 72 cases in 1962, there were 3275 cases in 2009 (Additional file 3 \& Figure 4), and the growth rate had reached $106 \%$ to $139 \%$ in the three most recent years. This trend was primarily the result of a continuous enlargement of the hospital and the neurosurgical department, with other possible reasons that will be discussed below. Gender differences were also noticeable. From 1962 to 2006, male patients seemed to be the susceptible population of CNS tumors, whereas over the last three years, the situation reversed. The female/male ratios were

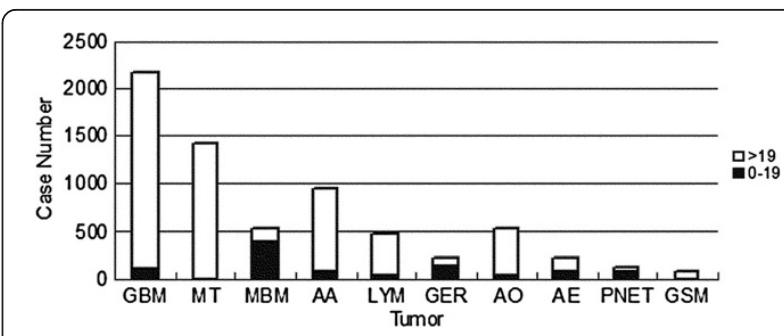

Figure 3 Some malignant tumors in children and elders from 1990 to 2009. GBM = Glioblastoma; MT = Metastatic Tumor; $\mathrm{MBM}=$ Medulloblastoma; $\mathrm{AA}=$ Anaplastic astrocytoma; $\mathrm{LYM}=$ Lymphoma; $\mathrm{GER}=$ Germinoma; $\mathrm{AO}=$ Anaplastic oligodendrocytoma; $\mathrm{AE}=$ Anaplastic ependymoma; $\mathrm{PNET}=$ Primitive neuroectodermal tumor; GSM = Gliosarcoma. 


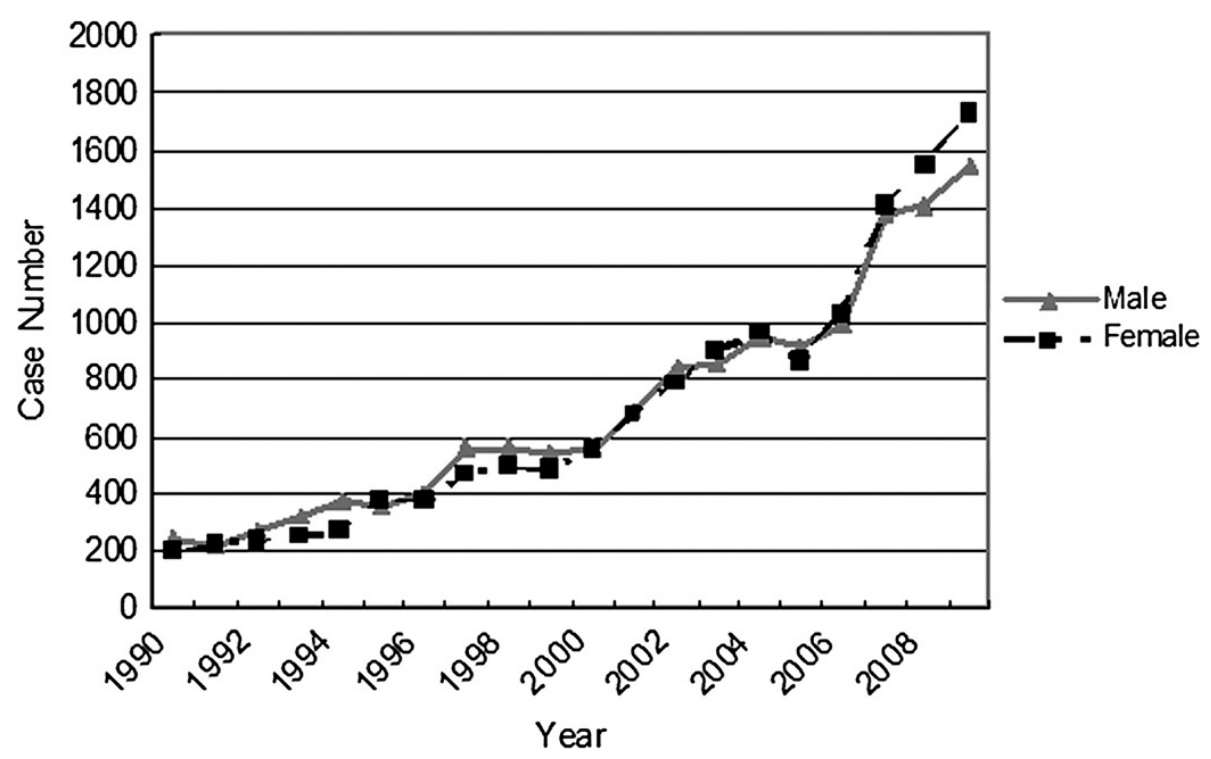

Figure 4 Time trends from 1990 to 2009 by sex.

$1.02,1.10$, and 1.12 from 2007 to 2009 , showing an increasing trend.

Although the incidence rates of all the CNS tumors increased rapidly, certain subtypes of these tumors exhibited remarkable increases (Figure 5). Lymphomas and hematopoietic neoplasms were 14.6-fold more common during 2005-2009 than during 1990-1994, whereas the incidence of all CNS tumors increased only 4.9-fold. The second highest increase in incidence was found for germ cell tumors (7-fold), followed by meningiomas (6-fold). The incidence of grade III-IV tumors increased much more rapidly than that of grade I-II tumors and the average incidence rate (Figure 6). The mean increase in neuroepithelial tumors was equal to the average increase, but diverse incidence rates existed among the subtypes. Oligodendrogliomas and oligoastrocytomas increased respectively 1.7 and 2.3 times faster than average (Figure 7). However, the distribution of neuroepithelial tumors, the most common category of CNS tumors, remained stable throughout the 20-year period (Figure 8).

\section{Discussion}

A retrospective epidemiological review of brain tumors is particularly important for future research because it can demonstrate the changes in the tumor spectrum of a population, reveal possible risk factors, and indicating potential therapy methods. China is the most populous country in the world, but it has not yet established a national incidence rate for CNS tumors. Over the past 20 years, acknowledged improvements have occurred in the economy and medical services in China, with concurrent environmental and lifestyle changes. Therefore, the epidemiological characteristics of China can be helpful for a worldwide study and may help predict possible future changes in undeveloped areas as they undergo development. Finally, because of the differences that are present in each classification edition, the

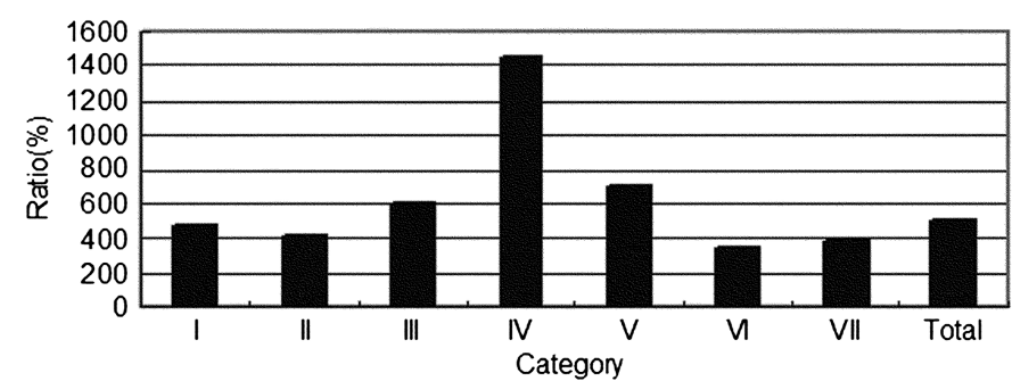

Figure 5 Growth rate of CNS tumors (90-94/05-09). I=Tumors of neuroepithelial tissue; $\|=$ Tumors of cranial and paraspinal nerves; III = Tumors of meninges; IV = Lymphomas and hematopoietic neoplasms; $V=$ Germ cell tumors; $V I=$ Tumors of the sellar region; $\mathrm{VII}=$ Metastatic tumors. 


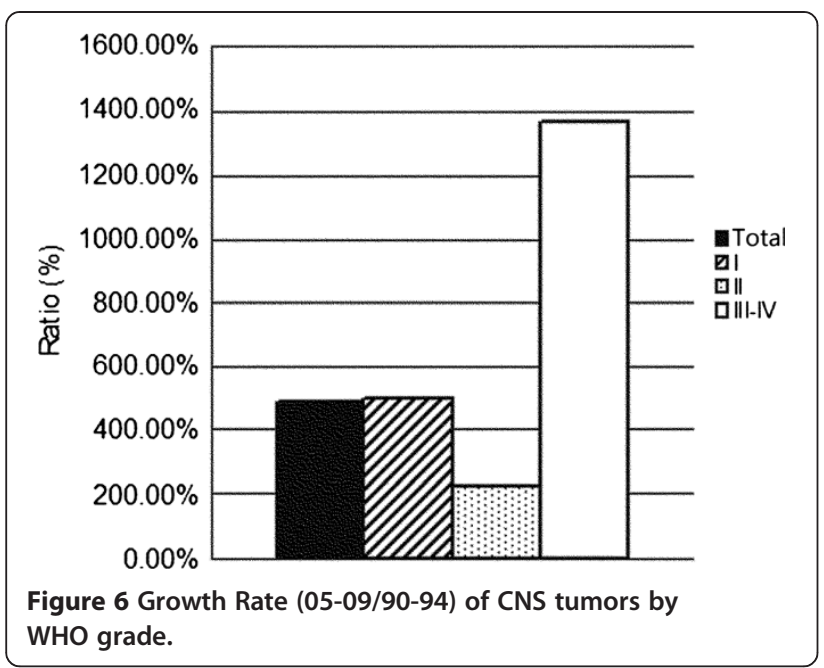

reassessment of past cases is required to update our knowledge of CNS tumors.

The distribution of CNS tumor categories found in this study did not exactly replicate the rates observed in previously published worldwide reports. Despite the selection bias inherent in this single-center study, tumors of neuroepithelial tissue and the meninges were the two most common categories; the proportions were $38.0 \%$ and $36.5 \%$, respectively. A nationwide database in France revealed that the proportions of these two categories were $53.9 \%$ and 28.8\%, respectively, from 2004-2008 [5], whereas another population-based report from CBTRUS (Central Brain Tumor Registry of the United States) recorded rates of $33.7 \%$ and 35.5\%, respectively, from 2004-2007 [6]. The reason for this great variation remains unknown and requires further investigation.

The tumor spectra varied from adults to children and teenagers as well as from males to females. According to the CBTRUS data, glioblastoma (17.7\%) and anaplastic astrocytoma $(2.1 \%)$ were the most common malignant tumors in adults. In this study population, metastatic tumor, glioblastoma, and anaplastic astrocytoma a larger proportion in adults, whereas medulloblastoma, germ cell tumors, and glioblastoma were more common among children and teenagers.
Among the pediatric cases, brain and spinal tumors have been shown to be the second most common cancers (20.2\%) in Shanghai, China, based on a previous regional study [7]. High proportions of astrocytomas (29.2\%) and medulloblastomas (12.3\%) were found in children and teenagers in our series, which seems to be in accordance with reports from other locations, such as Taiwan (populationbased study), France (population-based study), India (single-center study), and Brazil (single-center study) [8-11]. However, a population-based study in Japan reported a lower proportion of medulloblastomas relative to germ cell tumors and craniopharyngiomas [12], whereas in France $(8.6 \%)$ and India (5.2\%), ependymal tumors were observed at higher proportions relative to germ cell tumors $[8,9]$. Details are provided in Table 3. During the past 20 years, children under the age of 4 were not permitted admission to our center; therefore, the spectrum of pediatric CNS tumors in our series might be distorted. The epidemiological variability in the observed histopathology worldwide indicates that the origin of these tumors might be closely related to racial and environmental factors.

Overall, a larger proportion of males had malignant CNS tumors across all the age groups in this limited population. Data from CBTRUS also revealed a male/female incidence ratio of 1.38 during 2003-2007. For the neuroepithelial tumors, the ratio (male/female) was 1.47 compared to 1.25 (2004-2007) from CBTRUS. Therefore, according to this survey and to other regional studies [13-18], it can be assumed that males tend to have a higher incidence of CNS tumors. Because of the high incidence of neuroepithelial tumors in men, gender difference could be a starting research point that may lead to some valuable findings with respect to tumor origins and chemotherapy. Gender difference found for meninges tumors in our survey was also striking, although we found a ratio (female/male) of only $1.7 \mathrm{com}$ pared to the 2.68 ratio based on the CBTRUS data (20042007). However, due to the widespread use of advanced diagnostic technologies in China, we predict that this ratio will increase in the near future.

For children and teenagers, the male/female ratio for CNS tumors was 1.66 in the selected cases. Other studies around the world have reported similar ratios: 1.1 in France (population-based study), 1.31 in Japan (population-based

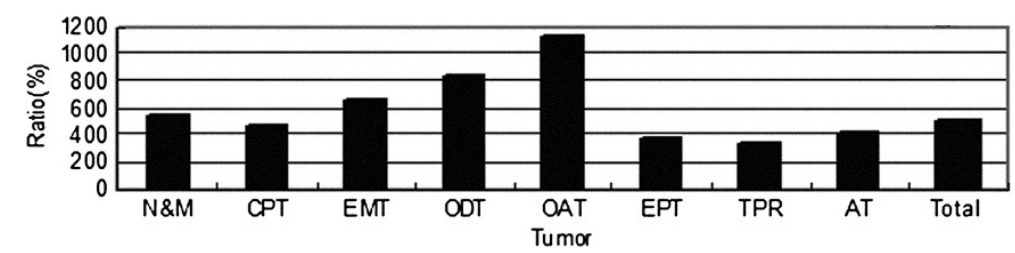

Figure 7 Growth rate of neuroepithelial tumors. $\mathrm{N} \& \mathrm{M}=$ Neuronal and mixed neuronal-glial tumors; CPT = Choroid plexus tumors; EMT = Embryonal tumors; ODT = Oligodendroglial tumors; OAT = Oligoastrocytic tumors; EPT = Ependymal tumors; TPR=Tumors of pineal region; AT $=$ Astrocytic tumors. 


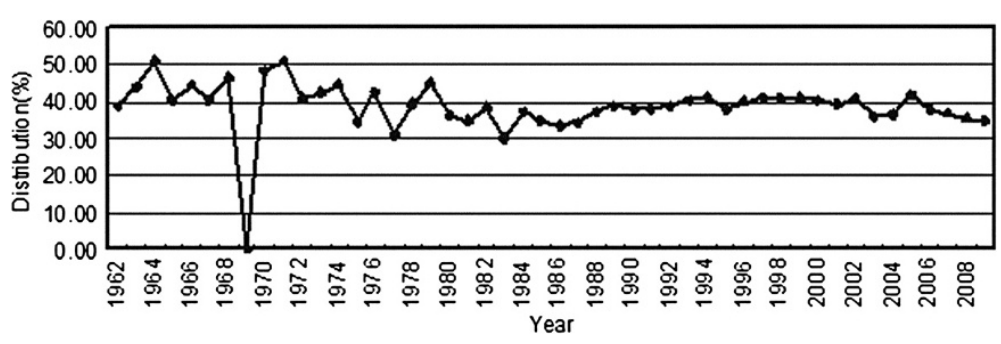

Figure 8 Distribution of neuroepithelial tumors by time.

study), and 1.27 in Brazil (single-center study) [9,10,12]. From our data, males accounted for $74.4 \%$ of the germ cell tumors in the pediatric cases, a percentage that was similar to the $69.6 \%$ reported by CBTRUS and to those reported by other studies from various regions [8-12], indicating that intrinsic factors also play important roles in oncogenesis.

Several studies have also revealed an increasing trend in the incidence rate for CNS tumors in western countries. In the United States, a population-based series showed that the annual percent change (APC) was $+1.1 \%$ from 1985 1999 [19], whereas in France, an APC of $+2.33 \%$ was observed from 2000 to 2007 [13]. Clinically silent CNS tumors have been identified in a larger proportion of the population, particularly among the elderly, because of improved imaging techniques $[17,20]$. Furthermore, the increasing trend was more prominent among certain CNS tumor subtypes [17,21-23]. xThe increased incidences of gliomas and meningiomas were suspected to have resulted from the widespread use of cell phones since the mid-1990s, but no causal association was confirmed [24,25]. A larger sample size, a uniform method of classification, and a longer observation time are necessary before we can reach a definitive conclusion.

In China, a fast-growing and developing country, increasing tumor morbidity has been blamed as one of the top three causes of death [1], just as in most western countries. Because it was not a population-based study, the APC in this series reached $+11.22 \%$. In part, this increase could be the result of the increase in hospital size, with the increased number of cases due to more sickrooms and operating rooms, improved neurosurgical techniques making more cases operable and treatable, and economic developments that result in more affordable therapy for most patients. Another key reason might be associated with an increased detection rate of CNS tumors after the widespread use of CT and MRI in both rural and urban areas in China, which reinforced the referral bias. In the early 1980s, the first CT machine was imported into Huashan hospital; this was also the first CT machine in China. In the late 1980s, the first MRI followed. Those machines contributed greatly to the diagnosis of CNS tumors, and from Additional file 3, we indeed observe a continuous increase in the number of cases during that period. Moreover, because the textile industry was booming in a developing China during the 1980s, women constituted the majority of textile workers. Therefore, occupation-related risk factors were simultaneously raised, and a case-cohort study showed a higher brain tumor incidence in female textile workers during that period in Shanghai [26]. The agreement with this data series suggests that the large and detailed database from our sample is very valuable because it reveals how quickly the CNS tumor spectrum changed in China with respect to the affected population characteristics.

The diverse growth rates of the CNS tumor subtypes are also very worthy of consideration. The fastest growing categories of tumors in this study included lymphomas, germ cell tumors, and tumors of the meninges. Lymphoma has been ranked as one of the top ten malignant tumors in this

Table 3 Proportions of top CNS tumor subtypes among children and teenagers in different regions

\begin{tabular}{|c|c|c|c|c|c|c|c|c|}
\hline \multirow[b]{2}{*}{ Country } & \multirow[b]{2}{*}{ Author } & \multirow[b]{2}{*}{ Period } & \multirow[b]{2}{*}{ Age(yrs) } & \multirow[t]{2}{*}{ Astrocytoma } & \multirow[t]{2}{*}{ Medulloblastoma } & \multirow[t]{2}{*}{ Craniopharyngioma } & \multirow{2}{*}{$\begin{array}{l}\text { Germ cell } \\
\text { tumors }\end{array}$} & \multirow{2}{*}{$\begin{array}{r}\text { Ependymal } \\
\text { tumours }\end{array}$} \\
\hline & & & & & & & & \\
\hline China & & 1990-2009 & $0-19$ & $29.2 \%$ & $13.1 \%$ & $12.3 \%$ & $8.1 \%$ & $6.2 \%$ \\
\hline Taipei & Wong et al. [11] & $1975-2004$ & $0-18$ & $36.9 \%$ & $15.8 \%$ & 9.8 & $12.7 \%$ & $6.8 \%$ \\
\hline Japan & Makino et al. [12] & $1989-2008$ & $0-15$ & $38.6 \%$ & $13.1 \%$ & 13.7 & $14.4 \%$ & $5.2 \%$ \\
\hline India & Asirvatham et al. [8] & 1990-2004 & $0-18$ & $49.7 \%$ & $12.0 \%$ & $10.3 \%$ & $3.0 \%$ & $5.2 \%$ \\
\hline France & Bauchet et al. [9] & 2004-2006 & 0-19 & $32.9 \%$ & $13.1 \%$ & $5.4 \%$ & $3.6 \%$ & $8.6 \%$ \\
\hline Brazil & Pinho et al. [10] & 1989-2009 & $0-21$ & $37.7 \%$ & $16.3 \%$ & $12.5 \%$ & $7.0 \%$ & $8.1 \%$ \\
\hline US & CBTRUS [6] & $2004-2007$ & $0-19$ & $33.1 \%$ & $12.0 \%$ & $3.6 \%$ & $4.8 \%$ & $6.7 \%$ \\
\hline
\end{tabular}


century, and it has the fastest growing incidence rate of all malignant tumors in China [27]. Despite the inherent biases, certain chemical pollutants should be carefully considered [28,29]. Germ cell tumors are also thought to be closely related to environmental factors. They exhibit a considerable geographical variation in incidence, representing $3-15 \%$ of all primary pediatric intracranial neoplasms [30]. Reports from Japan revealed a step-up increase in the incidence from 1980 to 1993 and indicated that winter-born children were more susceptible [31,32]. For the tumors of the meninges, increasing trends were observed around the world [13,17,19,21-23,31], and improvements in the diagnostic technologies are still considered to be the major causal factor. Worldwide studies have also demonstrated an apparently increased incidence of metastatic tumors [33], but this increase was less prominent in our series. The difference might be an artifact of this investigation, as this is a pathological-based review; thus, brain metastasis could have been detected earlier and have been well controlled by radiosurgery without pathological proof. According to our study, most of the fastest increasing subtypes were also malignant, which underscored our need to be more cautious. Therefore, we need more large-scale population-based studies to identify the real risk factors.

As a single-center retrospective series, the data in this study could not represent the national epidemiology of CNS tumors. The pathological diagnoses included in this study were only from patients under surgery or biopsy. Furthermore, surgical treatments were not commonly used in some advanced malignant tumors. Therefore, the distribution of some of the tumor subtypes might be artificially high or low due to the unclear denominator. In brief, various biases were unavoidable in this study, which means that the conclusions should be evaluated with caution.

\section{Conclusions}

This study retrospectively analyzed a large-scale and longterm pathological database from a single neurological center. Although it was not a large population study, and a selection bias inevitably existed, the rapidity of the observed changes in the CNS tumor spectrum with respect to the affected population characteristics in China could model similar changes that will occur in other developing countries.

\section{Additional files}

Additional file 1: Distribution of CNS Tumor Categories by Sex from 1962 to 1989.

Additional file 2: Distribution of CNS Tumor Categories by Age from 1962 to 1989. I= Tumors of neuroepithelial tissue; $\|=$ Tumors of cranial and paraspinal nerves; III = Tumors of meninges; IV = Lymphomas and hematopoietic neoplasms; $V=$ Germ cell tumors; $V I=$ Tumors of the sellar region; $\mathrm{VII}=$ Metastatic tumors.

Additional file 3: Time Trends from 1962 to 1989 by Sex.

\section{Competing interests}

The authors declare that they have no competing interests.

\section{Authors' contributions}

LZ: He has made substantial contributions to conception and design, and acquisition of funding. LC and XZ: They had made contributions equally to acquisition of data, analysis and interpretation of data, and drafting the manuscript. YW and YM: They had made contributions to revising the manuscript critically, and had given final approval of the version to be published. All authors read and approved the final manuscript.

\section{Acknowledgements}

This study was funded by Project supported by the National Science Foundation for Distinguished Young Scholars of China (Grant No. 81100860). We thank all the clinicians of the Neuropathology Department of Huashan Hospital who contributed to the reassessment of the large number of sections, and all the clinicians who contributed to data collection.

\section{Author details}

${ }^{1}$ Department of Neurosurgery, Huashan Hospital, Fudan University, 12 Wu Lu Mu Qi Zhong Road, Jing An District, Shanghai 200040, China. 'Department of Neuropathology, Huashan Hospital, Fudan University, 12 Wu Lu Mu Qi Zhong Road, Jing An District, Shanghai 200040, China.

Received: 10 October 2012 Accepted: 26 April 2013

Published: 2 May 2013

\section{References}

1. He J, Gu D, Wu X, Reynolds K, Duan X, Yao C, Wang J, Chen CS, Chen J, Wildman RP, Klag MJ, Whelton PK: Major causes of death among men and women in China. N Engl J Med 2005, 353(11):1124-1134.

2. Ferlay J, Bray F, Pisani P, Parkin DM: GLOBOCAN 2002: cancer incidence, mortality and prevalence worldwide, version 2.0. IARC cancerbase no. 5. IARC: Lyon; 2004.

3. Louis DN, Ohgaki H, Wiestler OD, Cavenee WK: WHO classification of tumours of the central nervous system. Lyon: IARC; 2007.

4. Rousseau A, Mokhtari K, Duyckaerts C: The 2007 WHO classification of tumors of the central nervous system - what has changed? Curr Opin Neurol 2008, 21(6):720-727.

5. Rigau V, Zouaoui S, Mathieu-Daudé H, Darlix A, Maran A, Trétarre B, Bessaoud F, Bauchet F, Attaoua R, Fabbro-Peray P, Fabbro M, Kerr C, Taillandier L, Duffau H, Figarella-Branger D, Costes V, Bauchet L: French brain tumor database: 5-year histological results on 25756 cases. Brain Pathol 2011, 21(6):633-644.

6. CBTRUS Statistical Report: Primary brain and central nervous system tumors diagnosed in the united states in 2004-2007. http://www.cbtrus.org/2011NPCR-SEER/WEB-0407-Report-3-3-2011.pdf.

7. Bao PP, Zheng Y, Wang CF, Gu K, Jin F, Lu W: Time trends and characteristics of childhood cancer among children age 0-14 in Shanghai. Pediatr Blood Cancer 2009, 53(1):13-16.

8. Asirvatham JR, Deepti AN, Chyne R, Prasad MS, Chacko AG, Rajshekhar V, Chacko G: Pediatric tumors of the central nervous system: a retrospective study of 1,043 cases from a tertiary care center in South India. Childs Nerv Syst 2011, 27(8):1257-1263.

9. Bauchet L, Rigau V, Mathieu-Daudé H, Fabbro-Peray P, Palenzuela G, Figarella-Branger D, Moritz J, Puget S, Bauchet F, Pallusseau L, Duffau H, Coubes $P$, Trétarre B, Labrousse F, Dhellemmes P: Clinical epidemiology for childhood primary central nervous system tumors. J Neurooncol 2009, 92(1):87-98.

10. Pinho RS, Andreoni S, Silva NS, Cappellano AM, Masruha MR, Cavalheiro S, Vilanova LC: Pediatric central nervous system tumors: a single-center experience from 1989 to 2009. J Pediatr Hematol Oncol 2011 33(8):605-609.

11. Wong TT, Ho DM, Chang KP, Yen SH, Guo WY, Chang FC, Liang ML, Pan HC, Chung WY: Primary pediatric brain tumors: statistics of Taipei VGH, Taiwan (1975-2004). Cancer 2005, 104(10):2156-2167.

12. Makino K, Nakamura H, Yano S, Kuratsu J: Population-based epidemiological study of primary intracranial tumors in childhood. Childs Nerv Syst 2010, 26(8):1029-1034.

13. Baldi I, Gruber A, Alioum A, Berteaud E, Lebailly P, Huchet A, Tourdias T, Kantor G, Maire JP, Vital A, Loiseau H: Descriptive epidemiology of CNS 
tumors in France: results from the gironde registry for the period 2000-2007. Neuro Oncol 2011, 13(12):1370-1378.

14. Filippini G: Epidemiology of primary central nervous system tumors. Handb Clin Neurol 2012, 104:3-22.

15. Nakamura H, Makino K, Yano S, Kuratsu J: Epidemiological study of primary intracranial tumors: a regional survey in Kumamoto prefecture in southern Japan-20-year study. Int J Clin Oncol 2011, 16(4):314-321.

16. Lonn S, Klaeboe L, Hall P, Mathiesen T, Auvinen A, Christensen HC Johansen C, Salminen T, Tynes T, Feychting M: Incidence trends of adult primary intracerebral tumors in four Nordic countries. Int J Cancer 2004, 108(3):450-455.

17. Staneczek W, Janisch W: Epidemiologic data on meningiomas in East Germany 1961-1986: incidence, localization, age and sex distribution. Clin Neuropathol 1992, 11(3):135-141.

18. Sanai N, Chang S, Berger MS: Low-grade gliomas in adults. J Neurosurg 2011, 115(5):948-965.

19. Hoffman S, Propp JM, McCarthy BJ: Temporal trends in incidence of primary brain tumors in the United States, 1985-1999. Neuro Oncol 2006, 8(1):27-37.

20. Nakasu S, Hirano A, Shimura T, Llena JF: Incidental meningiomas in autopsy study. Surg Neurol 1987, 27(4):319-322.

21. Christensen HC, Kosteljanetz M, Johansen C: Incidences of gliomas and meningiomas in Denmark, 1943 to 1997. Neurosurgery 2003, 52(6):13271333. discussion 1333-1324.

22. Greig NH, Ries LG, Yancik R, Rapoport SI: Increasing annual incidence of primary malignant brain tumors in the elderly. J Natl Cancer Inst 1990, 82(20):1621-1624.

23. Klaeboe L, Lonn S, Scheie D, Auvinen A, Christensen HC, Feychting M, Johansen C, Salminen T, Tynes T: Incidence of intracranial meningiomas in Denmark, Finland, Norway and Sweden, 1968-1997. Int J Cancer 2005, 117(6):996-1001.

24. Aydin D, Feychting M, Schüz J, Tynes T, Andersen TV, Schmidt LS, Poulsen AH, Johansen C, Prochazka M, Lannering B, Klæboe L, Eggen T, Jenni D, Grotzer M, Von der Weid N, Kuehni CE, Röösli M: Mobile phone use and brain tumors in children and adolescents: a multicenter case-control study. J Natl Cancer Inst 2011, 103(16):1264-1276.

25. Deltour I, Johansen C, Auvinen A, Feychting M, Klaeboe L, Schuz J: Time trends in brain tumor incidence rates in Denmark, Finland, Norway, and Sweden, 1974-2003. J Natl Cancer Inst 2009, 101(24):1721-1724.

26. Gold LS, De Roos AJ, Ray RM, Wernli K, Fitzgibbons ED, Gao DL, Astrakianakis G, Feng Z, Thomas D, Checkoway H: Brain tumors and occupational exposures in a cohort of female textile workers in Shanghai, China. Scand J Work Environ Health 2006, 32(3):178-184.

27. Zhang SW, Lei ZL, Li GL, Zou XN, Zhao P, Chen WQ: A report of cancer incidence and mortality from 34 cancer registries in china, 2006. Zhong Guo Zhong Liu 2010, 19:356-365.

28. Cooper GS, Scott CS, Bale AS: Insights from epidemiology into dichloromethane and cancer risk. Int J Environ Res Public Health 2011, 8(8):3380-3398.

29. Vinson F, Merhi M, Baldi I, Raynal H, Gamet-Payrastre L: Exposure to pesticides and risk of childhood cancer: a meta-analysis of recent epidemiological studies. Occup Environ Med 2011, 68(9):694-702.

30. Jorsal T, Rorth M: Intracranial germ cell tumours. A review with special reference to endocrine manifestations. Acta Oncol 2012, 51(1):3-9.

31. Kaneko S, Nomura K, Yoshimura T, Yamaguchi N: Trend of brain tumor incidence by histological subtypes in Japan: estimation from the brain tumor registry of Japan, 1973-1993. J Neurooncol 2002, 60(1):61-69.

32. Makino K, Nakamura H, Hide T, Kuratsu J: Risk of primary childhood brain tumors related to season of birth in Kumamoto Prefecture. Japan. Childs Nerv Syst 2011, 27(1):75-78

33. Alexandru D, Bota DA, Linskey ME: Epidemiology of central nervous system metastases. Prog Neurol Surg 2012, 25:13-29.

doi:10.1186/1472-6890-13-14

Cite this article as: Chen et al: Central nervous system tumors: a single center pathology review of 34,140 cases over 60 years. BMC Clinical Pathology 2013 13:14

\section{Submit your next manuscript to BioMed Central and take full advantage of:}

- Convenient online submission

- Thorough peer review

- No space constraints or color figure charges

- Immediate publication on acceptance

- Inclusion in PubMed, CAS, Scopus and Google Scholar

- Research which is freely available for redistribution

Submit your manuscript at www.biomedcentral.com/submit
C BioMed Central 